\title{
Application of Glucose Based Enzymatic Biofuel Cell in Biomedical Devices
}

\author{
Inamuddin* and Sufia ul Haque \\ Advanced Functional Materials Laboratory, Faculty of Engineering and Technology, Aligarh Muslim University, India \\ *Corresponding author: Inamuddin, Faculty of Engineering and Technology, Aligarh Muslim University, Aligarh, India
}

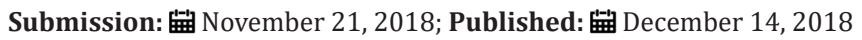

\begin{abstract}
In this review summary, efforts have been put to assimilate the results of research that employed the glucose based enzymatic biofuel cells in the biomedical applications. All the analysis involving studies and research have been done on mammals and fruits before it would be tried on human beings. As we know the issues associated with the pacemakers integrated with lithium batteries would provide the power to the device for few years after which the patient must undergo for the surgical replacement which would result in more bills to pay as well as the health risk due to the chances of infections. Thus, the scientists focused the research on the utilization of the ambient energy of the body to run the implanted biomedical devices for life long duration without any replacement.
\end{abstract}

\section{Introduction}

According to American Herb Association, about three million people worldwide implanted with pacemakers and 600,000 pacemakers being implanted each year Do \& Shivkumar [1], Leef et al. [2] and Nichols \& Vose [3]. Like several biomedical implants, the pacemakers require battery in order to perform. Today batteries and pacemakers expire into ten years after which the patient must undergo to the surgery for better replacement. As the number of population is increasing gradually the number of parallel replacement surgeries performed will increase. Leaving cardiac patient with more bills to pay and higher health risk due to chances of infection Hatfield et al. [4]. Scientists and researchers today are attempting to addresses the issue either by improving the current of batteries or by harvesting ambient body energy. These new sources of energy must display long term stability, biocompatibility, and the ability to be integrated into biomedical devices as well as be able to consistently provide sufficient power to run the biomedical implant efficiently. Recently, the research has focused on the harvesting of body energy by merely through enzymes and microbes. The principle behind enzymatic biofuel cells is the enzyme replaces metals to oxidize the fuel. A glucose-based biofuel cell based on enzymatic principles has so far been successfully implanted into rats Andoralov et al. [5]. These fuel cells almost run only on sugar and oxygen present in the body. Enzymatic biofuel cells are preferring promising due to be very inexpensive. However, due to difficulty in stabilizing the enzymes these fuel cells have short life time and poor power density.

Advancement towards the feasible utilization of glucose-based biofuel cells in implantable bioelectronic devices like drug delivery systems, cardio stimulators, and glucose biosensors have given a progressive direction to the researchers for biomedical applications Friedman \& Hayes [6], Grove [7] and Szczupak et al. [8]. Recently, carbon-based nanomaterials are used in the high-performance glucose-based biofuel cells as the electrode materials. The often utilization of these electrodic materials is due to their high surface area for a great amount of enzyme immobilization Reuillard et al. [9], Zebda et al. [10] and Gondran et al. [11]. Number of researches also revealed the transformation from in-vitro to in-vivo applications of enzymatic glucose-based biofuel cells Castorena et al. [12], MacVittie et al. [13], Schröder [14] and Southcott et al. [15].

\section{In-vivo applications of biofuel cells}

For in-vivo application, in 2010 Cinquin et al. [16] studied the performance of a mediated glucose oxidase bioanode fitted in the retroperitoneal space of a rat which produced the power density of $24.4 \mu \mathrm{Wcm}^{-3}$. On the other hand, Miyake et al. [17] successfully implanted a needle type bioanode into the vein of rabbit's ear and a biocathode implemented outside to minimize the extra $\mathrm{O}_{2}$ in air. These research works have contributed in the field of biofuel cell by providing an idea of subcutaneous implantation of enzymatic glucose-based biofuel cells.

In 2012, Ramussen et al. [18] decreased the complications of biofuel cell implantation by partially imbedded a two chambered biofuel cell consisting of bienzyme anode (GOx and trehalose) and bilirubin oxidase cathode in the gut of a cockroach. In this study, anode was implanted inside the body of the cockroach and the cathode was remain outside in order to circumvent the low amount of oxygen in the body with a maximum current density of $460 \mu \mathrm{Acm}^{-2}$. Also Falk et al. [19] and Wang et al. [20] prepared a 
biofuel cell bioanode consisted of cellobiose dehydrogenase and cathode modified with bilirubin oxidase fitted in lachrymal fluid of human which generated a power density of $1 \mu \mathrm{W}$. In 2013, the study showed a glucose-based biofuel cell fabricated from carbon nanotubes was implanted in the abdominal cavity of the rat. This implantation generated a stable power output of $193.5 \mu \mathrm{Wcm}^{-2}$ at a cell voltage of $0.57 \mathrm{~V}$ Reuillard et al. [9] and Zebda et al. [10]

Further in 2015, MacVittie et al. [21] obtained power from citrus fruit by utilizing a bucky paper altered with pyrroloquinoline quinone-dependent glucose dehydrogenase (PQQ-GDH) and flavin adenine dinucleotide (FAD) dependent fructose dehydrogenase at anode and laccase at the cathode. This system generated a current density of $0.33 \mathrm{mAcm}^{-2}$ with an open circuit voltage of $0.6 \mathrm{~V}$. On the other hand, in the same year another group of researchers implanted a trehalose oxygen biofuel cell in the Blaberus discoidalis. In which the energy accumulated in the hemolymph of tropical cockroach was observed to carry a power output of $0.12 \mu \mathrm{W}$ Schwefel et al. [22]. The various species of organisms such as cockroaches, molluscs, rat, rabbit and snails have been employed to analyze the performance of enzymatic glucose-based biofuel cells. To achieve the high potential for in-vivo applications of biofuel cells, some researchers used a cascade of enzyme for complete oxidation of fuel that can be connected in parallel or series to obtain the high power and current density. An electrode made of bucky paper modified with laccase and PQQ-GDH to achieve an open circuit voltage of $0.8 \mathrm{~V}$ with a maximum power of $5.2 \mu \mathrm{W}$ for a series combination and an open circuit voltage of $0.36 \mathrm{~V}$ with a power output of $37 \mu \mathrm{W}$ for a parallel combination. Hence, the enzymatic biofuel cells in series or parallel combination can be employed based on required electrical parameter. Recently, a glucose-based biofuel cell was implanted in a rabbit for duration of two months. In the end of second month the implanted biofuel cell had reduced power output which was most likely due to an inflammation. This study also exhibited the route which would increase the operational activity by minimizing the inflammatory processes El Ichi et al. [23]. Last but not least these studies set the trail to be followed in the development of selfpowered biomedical devices.

\section{Future scenario of in-vivo glucose-based biofuel cell applications}

The progress of implantable glucose-based biofuel cells made from a biological material for the generation of clean energy have a much higher probability of being long term stable and biocompatible. The energy obtained from the chemical part of the glucose in terms of electricity finds potential application to run the bioelectronic devices such as neurophysiological monitors, cardiac pacemakers, glucose sensing contact lenses and continuous glucose monitors Falk et al. [24]. Recently, a cardiac pacemaker powered by lithium batteries and is utilized to treat the abnormal heart rhythm. In general, these batteries get expiry in 5 to 10 years and required to be replaced Rapsang \& Bhattacharyya [25]. After 10 years patient requires a battery replacement via an open-heart surgery which cause the considerable cost of surgery and risk of infections to the patient Jeon et al. [26]. Thus, in this scenario a miniaturized glucose-based biofuel cells implemented inside the heart will use the power of glucose present in the stream of blood to run the pacemaker continuously as long as there is a perpetual supply of glucose with the consideration that the enzymes do not become inactive over time. Hence, number of efforts have been made to develop a glucose-based biofuel cell that will resolved the issue and provide a current to the devices used to maintain the human life.

\section{Conclusion}

Scientists are working upon the shortcomings of enzymatic biofuel cells with the future goals to be achieved are their smaller size, more efficient and long-lasting behavior. Researchers are currently looking for ways to stabilize enzymes which would thus allow enzymatic biofuel cells to become long lasting and easily implanted by providing an ease to patients with a lifelong energy through a biomedical device as well as scientists are trying to reduce the surgical costs and health treatment for a large number of people around the globe. With this new technology there could be fewer patients in need of regular hospital support and other areas of biomedical technology will be one step closer to a fiction and effective internal health support systems. These battery alternatives are healthy and clean while reducing current costs.

\section{References}

1. Do DH, Shivkumar K (2017) Programmable hypertension control: Another possible indication for implanted pacemakers. Journal of the American Heart Association 6(12): e008053.

2. Leef GC, Hellkamp AS, Patel MR, Becker RC, Berkowitz SD, et al. (2017) Safety and efficacy of rivaroxaban in patients with cardiac implantable electronic devices: Observations from the ROCKET AF Trial. Journal of the American Heart Association 6(6): e004663.

3. Nichols CI, Vose JG (2017) Incidence of bleeding-related complications during primary implantation and replacement of cardiac implantable electronic devices. Journal of the American Heart Association 6(1): e004263.

4. Hatfield LA, Kramer DB, Volya R, Reynolds MR, Normand ST (2016) Geographic and temporal variation in cardiac implanted electric devices to treat heart failure. Journal of the American Heart Association 5(8): $\mathrm{e} 003532$.

5. Andoralov V, Falk M, Suyatin DB, Granmo M, Sotres J, et al. (2013) Biofuel cell based on microscale nanostructured electrodes with inductive coupling to rat brain neurons. Scientific Reports 3(1): 3270.

6. Friedman PA, Hayes DL Cardiac pacing, defibrillation and resynchronization [electronic resource]: A clinical approach.

7. Grove WR (1839) XXIV. On voltaic series and the combination of gases by platinum. The London, Edinburgh, and Dublin Philosophical Magazine and Journal of Science 14(86-87): 127-130.

8. Szczupak A, Halámek J, Halámková L, Bocharova V, Alfonta L, et al. (2012) Living battery-biofuel cells operating in vivo in clams. Energy \& Environmental Science 5(10): 8891.

9. Reuillard B, Le Goff A, Agnès C, Holzinger M, Zebda A, et al. (2013) High power enzymatic biofuel cell based on naphthoquinone-mediated oxidation of glucose by glucose oxidase in a carbon nanotube 3D matrix. Physical Chemistry Chemical Physics 15(14): 4892-4896.

10. Zebda A, Cosnier S, Alcaraz JP, Holzinger M, Le Goff A, et al. (2013) Single glucose biofuel cells implanted in rats' power electronic devices. Scientific Reports 3(1): 1516. 
11. Gondran C, Zebda A, Le Goff A, Holzinger M, Cinquin P, et al. (2011) Mediator less high-power glucose biofuel cells based on compressed carbon nanotube-enzyme electrodes. Nature Communications 2(1): 370 .

12. Castorena GJA, Foote C, MacVittie K, Halámek J, Halámková L, et al. (2013) Biofuel cell operating in vivo in rat. Electroanalysis 25(7): 15791584.

13. MacVittie K, Halámek J, Halámková L, Southcott M, Jemison WD, et al. (2013) From "cyborg" lobsters to a pacemaker powered by implantable biofuel cells. Energy Environ Sci 6(1): 81-86.

14. Schröder U (2012) From in-vivo to in vivo-biofuel cells are maturing. Angewandte Chemie International Edition 51(30): 7370-7372.

15. Southcott M, MacVittie K, Halámek J, Halámková L, Jemison WD, et al. (2013) A pacemaker powered by an implantable biofuel cell operating under conditions mimicking the human blood circulatory systembattery not included. Physical Chemistry Chemical Physics 15(17): 6278-6283.

16. Cinquin P, Gondran C, Giroud F, Mazabrard S, Pellissier A, et al. (2010) A glucose biofuel cell implanted in rats. PLoS One 5(5): e10476.

17. Miyake T, Yoshino S, Yamada T, Hata K, Nishizawa M (2011) Selfregulating enzyme-nanotube ensemble films and their application as flexible electrodes for biofuel cells. Journal of the American Chemical Society 133(13): 5129-5134.

18. Rasmussen M, Ritzmann RE, Lee I, Pollack AJ, Scherson D (2012) An implantable biofuel cell for a live insect. Journal of the American Chemical Society 134(3): 1458-1460.
19. Falk M, Andoralov V, Blum Z, Sotres J, Suyatin DB, et al. (2012) Biofuel cell as a power source for electronic contact lenses. Biosensors and Bioelectronics, 37(1): 38-45.

20.Wang X, Falk M, Ortiz R, Matsumura H, Bobacka J, et al. (2012) Mediatorless sugar/oxygen enzymatic fuel cells based on gold nanoparticle-modified electrodes. Biosensors and Bioelectronics 31(1): 219-225.

21. MacVittie K, Conlon T, Katz E (2015) A wireless transmission system powered by an enzyme biofuel cell implanted in an orange. Bioelectrochemistry 106A: 28-33.

22. Schwefel J, Ritzmann RE, Lee IN, Pollack A, Weeman W, et al. (2014) Wireless communication by an autonomous self-powered cyborg insect. Journal of the Electrochemical Society 161(13): H3113-H3116.

23. El Ichi RS, Alcaraz JP, Boucher F, Boutaud B, Dalmolin R, et al. (2018) Remote wireless control of an enzymatic biofuel cell implanted in a rabbit for 2 months. Electrochimica Acta 269: 360-366.

24. Falk M, Andoralov V, Silow M, Toscano MD, Shleev S (2013) Miniature biofuel cell as a potential power source for glucose-sensing contact lenses. Analytical Chemistry 85(13): 6342-6348.

25. Rapsang AG, Bhattacharyya P (2014) Pacemakers and implantable cardioverter defibrillators-general and anaesthetic considerations. Brazilian Journal of Anesthesiology 64(3): 205-214.

26. Jeon D, Chen YP, Lee Y, KimY, Foo Z, et al. (2014) 24.3 An implantable 64nW ECG-monitoring mixed-signal SoC for arrhythmia diagnosis. In 2014 IEEE International Solid-State Circuits Conference Digest of Technical Papers (ISSCC), IEEE, pp. 416-417.

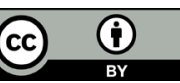

Creative Commons Attribution 4.0 International License

For possible submissions Click Here

\section{Submit Article}

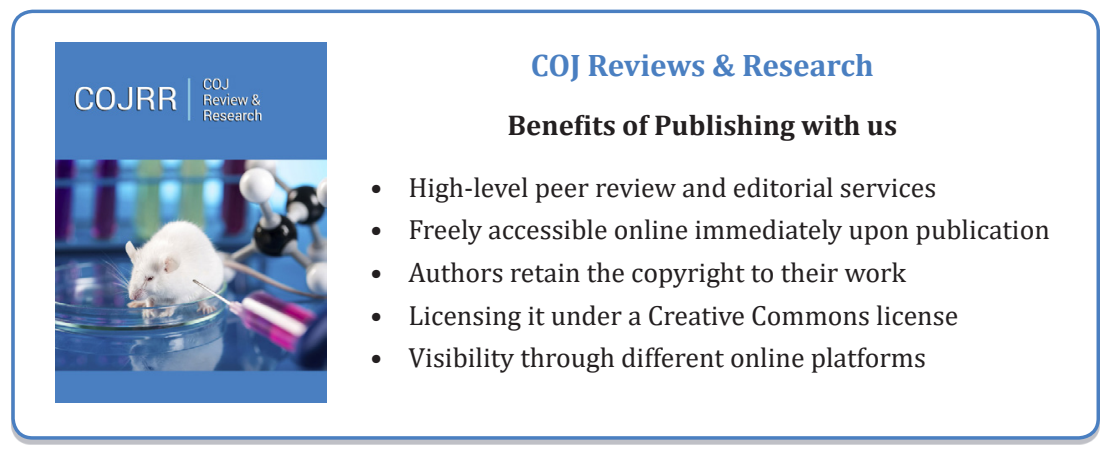

